1. Design and implement a research project using a qualitative methodology

2. Present the descriptions of spiritual care from the perspective of staff and volunteers and patients/families in the form of an organisational statement and strategy

3. Identify patterns and subsequent themes which emerge from the staff and volunteer perspective

4. Identify and share relevant findings to support the introduction of the spiritual care champion role

5. Identify and share relevant findings to support the introduction of feedback from patients and their families about their experience

6. Design an introduction to spiritual care for the induction of all staff and volunteers

7. Implement a spiritual care assessment tool for staff

8. Share this research with the wider community through connecting with the multi faith network surrounding a UK Hospice and thus increase (community) engagement via this network

9. Share learning within the hospice movement.

\section{P-150 GATHERING REAL-TIME PATIENT SATISFACTION FEEDBACK USING AN ELECTRONIC TABLET-BASED APPLICATION}

Clare Williams, Judith Park. St Luke's Hospice, Sheffield, UK

\subsection{6/bmjspcare-2016-001245.173}

Background Hospices are increasingly expected to collect data from service users in order to demonstrate the quality of the care provided. However, there can be challenges in gathering feedback from patients who may be too ill or fatigued to complete lengthy surveys. Additionally, by the time paper-based surveys are processed, important issues and concerns may have been missed. Many hospitals are now using portable electronic devices to obtain patients' views, but this approach is seldom used in hospices.

Aim To use a short electronic survey to gather feedback from hospice in-patients and day patients.

Method Patients use a tablet computer to rate statements about their care using a standard scale. The statements are based on the National Institute for Health and Care Excellence quality standards for end of life care. Patients complete the survey either by themselves or with assistance, simply touching the screen to indicate their responses. A free text box allows patients to make comments. Results are transmitted wirelessly to a relevant staff member within two minutes of the survey being completed.

Results Between January 2015 and April 2016, 200 in-patients and 46 day patients completed a survey. The results show a generally high level of satisfaction with care. The real-time nature of the feedback allows us to act quickly on any issues - for example, comparing the time and date of any negative feedback about nurse response times with the actual call times and staffing levels for that day. Results are used to inform future planning and contribute to staff training. Patients find the survey easy and quick to complete.

Interpretation and conclusions We continue to gather data using the survey on an ongoing basis. It enables us to continually monitor patient satisfaction, covering a large percentage of our inpatients and day patients, and address problems swiftly.

\section{P-151 \\ THE CHERRY ON THE CAKE: WORK WITH A SERVICE USER GROUP MAKING A REAL DIFFERENCE TO PERSONALISED CARE}

Fiona Smith, Sandra Pelan. Sue Ryder Care, Cheltenham, UK

\subsection{6/bmjspcare-2016-001245.174}

Involving users in the development and evaluation of services is an indispensable way of ensuring quality healthcare provision (Help the Hospices, 2013). Our aim was to create a Service User Group that would become an important resource for the hospice and to try to identify the extra things that would make a difference for our patients' experience.

Over the last 18 months our group has been pivotal in introducing the following new initiatives:

- Just in Case folders - Patients are now discharged home with a folder for district nurses that contains injectable medication, a prescription chart, advice on medication and a satisfaction survey.

- Personalising the bed space - patients asked for a way to personalise their bed space with photos and personal items. A magnetic board is now at each bedside for patients' personal use.

- Patient Information Booklet - a detailed information booklet of who's who and daily hospice life is now at each patient's bedside, this has been written by the user group.

- Mugs - Our hospice mugs for patient and visitors were very plain; we now plan to introduce a variety of styles of mugs.

- A medication chart - is currently under development, to help patients to monitor their medication on discharge.

Our recommendations from working with this group are:

- Start small and build on this, even if you only have one service user their contribution can be invaluable

- The user group needs to be promoted locally via web page, Facebook, Twitter and the local press

- Create a lively useful agenda with speakers

- Ensure actions are taken forward and fed back at the next meeting

- Ensure the group remains in the forefront of colleagues' minds as they create new leaflets or change their services.

\section{P-152 TALK TO US, A PARTNERSHIP APPROACH TO UNDERSTANDING THE EXPERIENCES OF CARE DURING THE LAST YEAR OF LIFE}

Lisa Gibson. St Barnabas Hospice, Grantham, UK

\subsection{6/bmjspcare-2016-001245.175}

The National VOICES survey of bereaved people told us that for many people in Lincolnshire palliative and end-of-life care was not meeting expectations.

In 2012 a bereaved person began conversation with Lincolnshire West Clinical Commissioning Group about the care his wife had received. His insight highlighted how vital a good understanding of patient experience is to informing and influencing system wide change.

An earlier study using St Barnabas volunteers evidenced that the use of volunteers in collecting data, in a peer to peer exchange, provides unprecedentedly rich information.

In November 2014 we drew this learning together to launch the Public and Patient Participation Project, latterly referred to as 